\title{
A capacidade de vocalização dos Conselhos Tutelares em Santa Catarina $^{1}$
}

\author{
Maria Salete da Silva ${ }^{2}$
}

- Enviado em 20/12/2015

- Aprovado em 30/05/2016

\section{RESUMO}

Este artigo trata da capacidade de vocalização dos Conselhos Tutelares no Sistema de Garantia de Direitos da Criança e do Adolescente em Santa Catarina. A capacidade de vocalização é o que permite tornar visível a violação de direitos de crianças e de adolescentes, dando-lhes voz e, ao mesmo tempo, demarcar sua posição em defesa do cumprimento dos direitos fundamentais conforme dispõe o Estatuto da Criança e do Adolescente. O percurso metodológico incluiu a realização de pesquisa qualitativa, com coleta de dados por meio da observação participante em seminários de formação e em reuniões promovidas pela Associação Catarinense de Conselheiros Tutelares. Tomamos o Sistema de Garantia de Direitos como uma configuração no interior da qual o Conselho está se constituindo ao travar relações de interdependência com os demais componentes em face da incompletude institucional. Definimos o Conselho Tutelar como uma instituição híbrida, traço decorrente de sua finalidade e características conforme indicadas na legislação que o criou, potencializada pela infraestrutura disponível para a sua instalação e funcionamento e pela rede de proteção formada pelas políticas públicas. Do entrecruzamento destes elementos estruturantes resulta uma identidade fronteiriça, conferindo-lhe um lugar entre a defesa de direitos e a reiteração da violação. Em Santa Catarina, os conselheiros evidenciaram as deficiências na rede de proteção à criança e ao adolescente, especialmente nas políticas de assistência social, educação e saúde. Todavia, as lacunas denunciadas não geraram ações que indicassem o exercício da capacidade de exigibilidade para garantir a restituição dos direitos violados.

Palavras-chave: Sistema de Garantia de Direitos da Criança e do Adolescente. Conselho Tutelar. Capacidade de vocalização. Configuração.

\section{INTRODUÇÃO}

O objetivo deste artigo é discorrer sobre a capacidade de vocalização do Conselho Tutelar no Sistema de Garantia de Direitos dos municípios de Santa Catarina, expressa pelas lacunas

\footnotetext{
${ }^{1}$ Tese de Doutorado em Sociologia defendida em 2011, sob orientação da Profa. Dra. Maria Tarcisa Silva Bega. Versão completa disponível na Biblioteca da Digital $\quad$ UFPR: acervodigital.ufpr.br/.../TESE_Conselhos_Tutelares_Santa_Catarina_dezembro_2011 >.
}

${ }^{2}$ Docente do Curso de Serviço Social da Universidade Regional de Blumenau (FURB). Doutora em Sociologia. mssilva@furb.br 
apontadas pelos conselheiros nos serviços de proteção ${ }^{3}$. Importa demonstrar como os Conselhos Tutelares catarinenses se posicionam no Sistema de Garantia de Direitos, mais especificamente, como se manifesta sua capacidade de vocalização, definida como a capacidade para tornar visível a violação de direitos das crianças e dos adolescentes, dando-lhes voz, e para demarcar sua posição em defesa do cumprimento de seus direitos fundamentais. Capacidade que está relacionada à geração de poder e ao empreendimento de lutas simbólicas para mostrar determinadas realidades e dar-lhes visibilidade, conforme Bourdieu (1987).

Segundo Baptista (2012, p. 191), o sistema de garantia de direitos está configurado em cinco eixos: “- da instituição do direito; II - da sua defesa; III - da sua promoção; IV - do controle de sua efetivação; e V - de sua disseminação (que seria responsável pela última estratégia referida na deliberação: a mobilização social em favor da garantia de direitos).”

Destaca-se o eixo da defesa do direito, do qual fazem parte as instituições que constituem "a via do acesso à justiça", a fim de garantir a efetividade dos direitos instituídos (BAPTISTA, 2012, p. 193). Dentre estas instituições, na esfera administrativa, situa-se o Conselho Tutelar (CT), definido no Art. 131 do Estatuto da Criança e do Adolescente (ECA) como "órgão permanente e autônomo, não jurisdicional, encarregado pela sociedade de zelar pelo cumprimento dos direitos da criança e do adolescente" (BRASIL, 2010).

Inicialmente, de acordo com o Art. 132 do ECA, foi previsto, pelo menos, um CT em cada município. Posteriormente, o CONANDA (2001) recomendou a instalação de um CT para cada 200 mil habitantes ou em densidade populacional inferior naqueles organizados por regiões administrativas, ou cuja extensão territorial indicasse a necessidade. Em 2010, a recomendação aprovada pelo CONANDA reduziu a proporção sugerindo um CT para cada 100 mil habitantes, fundamentando-se na diversidade dos municípios brasileiros no tocante à densidade populacional, extensão territorial e aos indicadores sociais.

O CT é composto de cinco membros, os quais devem cumprir requisitos mínimos como: idoneidade moral, idade superior a 21 anos e residir no município (Art. 133) e submeter-se a processo de escolha pela comunidade local para cumprimento de mandato de quatro anos, a partir

\footnotetext{
${ }^{3} \mathrm{O}$ conteúdo abordado neste artigo constitui um recorte da tese intitulada $\mathrm{Na}$ fronteira da defesa de direitos: a capacidade de vocalização dos Conselhos Tutelares de Santa Catarina, defendida no Programa de Pós-Graduação em Sociologia em 2011 e disponível na Biblioteca Digital da UFPR.
} 
de 2016 ${ }^{4}$. (BRASIL, 2012). Suas atribuições constam no Art. 95 e no Art. 136 do Estatuto da Criança e do Adolescente (BRASIL, 2010, p. 39). O Art. 95 confere-lhe a competência de fiscalizar as entidades governamentais e não-governamentais que executam programas de orientação e apoio sociofamiliar, apoio socioeducativo em meio aberto, colocação familiar, acolhimento institucional, liberdade assistida, semiliberdade e internação ${ }^{5}$ (BRASIL, 2010). A fiscalização não é prerrogativa específica do CT, mas é compartilhada pelo Ministério Público e Poder Judiciário, estando prevista dentro dos limites do que propõe o Art. 90, além de ser preventiva, já que as medidas relativas às irregularidades identificadas são do escopo do Poder Judiciário. O CT, como órgão administrativo, não aplica penalidades por crime ou infrações, nem substitui a ação de outros órgãos fiscalizadores. Diante de situações como estas, o CT representa à autoridade competente, mediante descrição dos fatos.

Mas as atribuições que conferem maior visibilidade ao CT estão descritas no Art. 136 do ECA, as quais são:

I - atender as crianças e adolescentes nas hipóteses previstas nos arts. 98 e 105, aplicando as medidas previstas no art. 101, I a VII;

II - atender e aconselhar os pais ou responsável, aplicando as medidas previstas no art. 129, I a VII;

III - promover a execução de suas decisões, podendo para tanto: a) requisitar serviços públicos nas áreas de saúde, educação, serviço social, previdência, trabalho e segurança; b) representar junto à autoridade judiciária nos casos de descumprimento injustificado de suas deliberações.

IV - encaminhar ao Ministério Público notícia de fato que constitua infração administrativa ou penal contra os direitos da criança ou adolescente;

V - encaminhar à autoridade judiciária os casos de sua competência;

VI - providenciar a medida estabelecida pela autoridade judiciária, dentre as previstas no art. 101, de I a VI, para o adolescente autor de ato infracional;

VII - expedir notificações;

VIII - requisitar certidões de nascimento e de óbito de criança ou adolescente quando necessário;

IX - assessorar o Poder Executivo local na elaboração da proposta orçamentária para planos e programas de atendimento dos direitos da criança e do adolescente;

$\mathrm{X}$ - representar, em nome da pessoa e da família, contra a violação dos direitos previstos no art. 220, $\S 3^{\circ}$, inciso II da Constituição Federal;

XI - representar ao Ministério Público para efeito das ações de perda ou suspensão do poder familiar, após esgotadas as possibilidades de manutenção da criança ou do adolescente junto à família natural.

Parágrafo único. Se, no exercício de suas atribuições, o Conselho Tutelar entender necessário o afastamento do convívio familiar, comunicará incontinenti o fato ao Ministério Público, prestando-lhe informações sobre os motivos de tal entendimento e as providências

\footnotetext{
${ }^{4} \mathrm{O}$ mandato era de três anos.
}

${ }^{5}$ Estes programas estão descritos no Art. 90 do Estatuto da Criança e do Adolescente. 
tomadas para a orientação, o apoio e a promoção social da família. (BRASIL, 2010, p. 3940).

A realização destas atribuições por parte do CT coloca-o em contato direto com crianças, adolescentes e suas famílias demandantes por direitos ou quando denunciadas em virtude do não cumprimento de seus deveres, especialmente os pais ou responsável legal, além das demais instituições do Sistema de Garantia de Direitos, quando suas ações incidirem em ameaça ou violação.

As atribuições do CT guardam distinções importantes, pois algumas estão diretamente relacionadas ao atendimento de crianças e adolescentes com direitos ameaçados ou violados, ao aconselhamento de seus respectivos pais e a aplicação de medidas correspondentes. Outras têm como foco o Poder Judiciário e o Ministério Público, no sentido de provocar a ação destes órgãos, como encaminhar e representar e, ainda, outras são dirigidas aos órgãos do poder executivo, como requisitar serviços e prestar assessoria na elaboração da proposta orçamentária de modo a garantir recursos para os programas e serviços que atendam os direitos fundamentais.

Em Santa Catarina, até meados da década de 1990, estavam instalados 103 Conselhos Tutelares, passando para 142 no período entre agosto de 1995 e dezembro de 1996, por força do Inquérito Civil 001/95 (GOMES NETO, 2004). Em 1998, 86\% dos municípios tinham este órgão instalado e, em 2009, as informações da pesquisa Perfil dos Municípios Brasileiros (IBGE, 2010) indicaram a existência de Conselhos Tutelares em todos os municípios catarinenses.

Para entender como os Conselhos Tutelares exercitam sua capacidade de vocalização em defesa dos direitos de crianças e de adolescentes em Santa Catarina, foi realizada pesquisa de campo, com coleta de dados através da observação direta. A coleta de dados por meio da observação participante dá-se com a "presença constante do observador no contexto observado", mediante a "interação face a face", por um período determinado, sendo que o observador pode ser "revelado ou encoberto" (HAGUETTE, 1987, p. 63).

No nosso caso, nos inserimos entre os conselheiros tutelares como um observador "revelado", e o fato de não termos vivenciado a experiência de "ser conselheiro tutelar" já era um indicativo de que éramos "alguém de fora", cuja estranheza era dada pela condição de nãoconselheira. Ao optarmos pela observação participante nosso intuito era acompanhar os conselheiros em seus contextos e em interação com outros atores do Sistema de Garantia de Direitos, a fim de reunir informações que pudessem contribuir na compreensão da capacidade de 
vocalização dos Conselhos Tutelares, bem como dos mecanismos utilizados para a defesa dos direitos fundamentais de crianças e adolescentes.

A observação ocorreu durante as atividades para capacitação de agentes do sistema de garantia de direitos organizados pela Associação Catarinense de Conselheiros Tutelares (ACCT) realizados no ano de 2010. Tivemos a oportunidade de acompanhar as atividades e ouvir suas dúvidas, críticas e angústias, sobretudo, pela ausência de reconhecimento de crianças e adolescentes como prioridade por parte do Estado, por presenciarem a reprodução da violação de direitos e pelas condições de trabalho precarizadas que obstaculizam o desempenho de suas atribuições ${ }^{7}$. Mas também presenciamos manifestações de satisfação por se sentirem partícipes de um dos mecanismos de proteção, o que, para muitos, era o argumento principal para enfrentarem as dificuldades e permanecerem conselheiros.

Inserimo-nos no campo com a preocupação de entender como os Conselhos Tutelares se manifestavam em defesa dos direitos de crianças e de adolescentes. Portanto, os dados empíricos foram obtidos durante o processo de observação que se estendeu por sete meses, incluindo a participação em: 13 seminários regionais; uma assembleia geral extraordinária; seis reuniões com integrantes das coordenações regionais; um seminário estadual; um encontro estadual de Conselhos Tutelares e de Direitos; um curso de capacitação para uso do SIPIA-CT Web ${ }^{8}$ e no planejamento estratégico da ACCT.

O registro dos dados foi feito em diário de campo e sob duas formas, no decorrer das atividades e, em seguida, complementado com impressões e descrições mais precisas. Não desconsideramos, no entanto, a possibilidade de ocorrência de "obliteração da percepção" do observador em face "do seu envolvimento na situação pesquisada" (HAGUETTE, 1987, p. 67). Por conseguinte, preocupamo-nos com o risco de selecionar alguns dados como relevantes e omitir ou desconsiderar outros. Por isso, nosso retorno aos registros foi uma atitude constante a fim de garantir que expressassem, de modo mais preciso possível, os fatos e as manifestações dos sujeitos.

\footnotetext{
${ }^{6}$ A ACCT foi fundada em 27 de outubro de 1995, durante o I Encontro Estadual de Conselhos Municipais e Tutelares dos Direitos da Criança e do Adolescente, mas a aprovação do seu Estatuto Social deu-se em 1999, na II Assembleia Geral da Associação, realizada na cidade de Curitibanos - SC. (SANTA CATARINA, 2002).
}

${ }^{7}$ Este debate não será realizada em razão dos limites deste artigo.

\footnotetext{
${ }^{8}$ Sistema de Informação para a Infância e Adolescência utilizado pelo CT.
} 
Para efeitos deste artigo, serão abordadas as Medidas de Proteção e as Medidas Pertinentes aos Pais ou Responsável aplicadas pelo CT e as violações e lacunas na rede de proteção à criança e ao adolescente que foram vocalizadas pelos conselheiros tutelares de Santa Catarina. Por fim, serão apresentadas as considerações finais e as referências bibliográficas.

\section{AS MEDIDAS DE PROTEÇÃO E AOS PAIS OU RESPONSÁVEL APLICADAS PELO CONSELHO TUTELAR}

A Política de Proteção Integral à Infância e Adolescência compõe-se de diretrizes para serem adotadas pelas políticas setoriais em consonância com "os direitos fundamentais inerentes à pessoa humana", conforme o Art. $3^{\circ}$ e citados no Art. $4^{\circ}$ do Estatuto da Criança e do Adolescente (BRASIL, 2010, p. 1), o que lhe confere caráter intersetorial. A Resolução nº 42 (CONANDA, 1995), define estas diretrizes como afetas às políticas de saúde, educação, assistência social e trabalho, mas a sua efetivação está estreitamente ligada a outras áreas, como a segurança pública e a habitação, por exemplo. A finalidade destas diretrizes é garantir que crianças e adolescentes transitem por todas as políticas sociais, constituindo-se como uma rede de proteção que respeite as suas peculiaridades e atenda seus direitos fundamentais.

Falar da rede de serviços nos remete ao Sistema de Garantia de Direitos, sobretudo, ao eixo de promoção, responsável pela execução de serviços de política pública nas áreas que abrangem os direitos fundamentais de crianças e adolescentes, bem como aos serviços extensivos às famílias. $\mathrm{O}$ CT aplica Medidas aos Pais ou Responsável, bem como são estes os responsabilizados pelo cumprimento das Medidas de Proteção aplicadas às crianças e aos adolescentes.

O eixo de promoção de direitos compõe uma parte do que é chamado de rede de proteção à criança e ao adolescente. Sendo essa acrescida das instituições do eixo de defesa, por terem uma atuação mais diretamente vinculada aos direitos individuais e coletivos. Afirmamos isso considerando que o eixo de controle social está centrado na participação da sociedade na formulação e acompanhamento das políticas sociais e não na prestação direta de serviços, exceto o CT, pois sua atuação na defesa de direitos interpenetra-se ao controle social.

O Sistema de Garantia de Direitos constitui uma configuração de instituições agrupadas em torno da proteção aos direitos de crianças e adolescentes, caracterizadas pela incompletude e, por 
essa razão, em permanente relação de interdependência e, ao mesmo tempo, permeada por cooperação, disputa, tensão e conflito. A ideia de configuração está associada ao entrançamento e à interconexão, isso significa que as organizações que compõem o Sistema de Garantia não estão simplesmente dispostas na mesma base territorial ou prestam atendimento a um mesmo grupo. É por isso que não basta a mera existência de uma multiplicidade de organizações para que possamos falar em rede de serviços de proteção social à criança e ao adolescente.

A rede que aqui nos referimos é o modo como as instituições do eixo de promoção estão articuladas, se relacionam entre si e com os demais componentes do Sistema de Garantia de Direitos. Em outras palavras, a rede de proteção social se constitui na proporção em que se estabelecem relações de interdependência do tipo cooperativas com vistas à proteção integral, o que não exclui níveis de tensão e disputa. Pois a interdependência está representada na imagem de uma rede, onde os fios possuem pontos de interseção e, por meio deles, encontram-se interligados (ELIAS, 1994).

A flexibilidade é uma característica dos fios que tecem a rede, por isso a proteção está prevista em graus distintos de intensidade no que tange à promoção e à restituição de direitos, desde ações antecipatórias, que visam prevenir a violação, até ações compensatórias, destinadas à restituição daquilo que já foi objeto de negação. Por outro lado, os fios que tecem as redes e interconectam as instituições podem se apresentar esgarçados ou rompidos, implicando em baixa proteção, ou podem prover alto grau de proteção e, ao mesmo tempo, adequar-se às novas demandas.

As redes de proteção social, na dimensão da atuação entrelaçada, constituem alternativas "quando a rede de referência do sujeito [especialmente a família] demonstra impossibilidade de desenvolver suas tarefas de cuidado ou de lidar com expressões particulares de sofrimento de seus membros" (MIOTO, 2000, p. 56). Constitui um exemplo as situações de violência intrafamiliar, sobretudo, quando estão associados a fatores agravantes como as condições precárias de existência, o uso abusivo ou a dependência em substância psicoativa. Nesse aspecto reside a relevância da rede secundária, composta de instituições entrançadas em torno de uma mesma finalidade, "prestar apoio real e duradouro a um indivíduo ou a uma família" (MIOTO, 2000, p. 55). Além do mais, a atuação em rede possibilita coletivizar os problemas, aparentemente individuais, e concretizar um processo de participação e de construção de ações coletivas para o seu enfrentamento, o que é pertinente ao 
Sistema de Garantia de Direitos. Por certo, a constituição de redes é uma alternativa para romper com modelos de atenção cristalizados das instituições, com atuações fragmentadas e sobrepostas.

A rede de serviços de proteção social à criança e ao adolescente constitui um elemento estruturado e estruturante das práticas do CT, pois a sua existência e o modo como está entrelaçada influencia na aplicação de medidas restitutivas. A aplicação de uma medida pode ter como critério a sua adequação à restituição do direito violado ou a disponibilidade do serviço na rede de proteção. Do mesmo modo, a inexistência de serviços correspondentes às medidas de proteção ou o esgarçamento da rede constituem objeto de sua intervenção, seja pela requisição ou pela assessoria ao executivo municipal para elaboração do orçamento, implantação, ampliação ou melhoria da qualidade dos serviços.

O CT atua diante da ameaça e/ou da violação dos direitos fundamentais de crianças e adolescentes por parte da família, da sociedade e do Estado ou em razão de sua própria conduta, segundo o Art. 98 do ECA (BRASIL, 2010). Recebe e averigua notícias de ameaça ou de prática de maus-tratos, como agressão física e psicológica, abuso sexual, negligência, abandono material, utilização na mendicância, exploração sexual e no trabalho, não acesso a serviços, entre outras.

Para tanto, precisa coletar informações na família, nos serviços de saúde, educação e outros a que a família esteja vinculada, bem como na própria comunidade. Durante o processo de averiguação das denúncias, o CT pode solicitar assessoria de profissionais da rede a fim de melhor aplicar as medidas diante da confirmação da suspeita de violação de direitos. Pois o objetivo de seu procedimento é identificar se há direitos ameaçados ou violados e quais, não cabendo elaborar diagnósticos e prescrever plano de intervenção. Sua referência é o conjunto de direitos de que são portadores as crianças e os adolescentes e os responsáveis pelo seu cumprimento.

Confirmada a ameaça ou a violação, o CT aplica Medidas de Proteção às crianças e aos adolescentes e/ou aos Pais ou Responsável. Sua atribuição é aplicar as Medidas e não executá-las, incumbência dos programas das políticas sociais, sob pena de incorrer na expansão de suas ações para além da sua finalidade. Por conseguinte, o acionamento da rede de serviços de proteção que integra o Sistema de Garantia de Direitos é uma condição para a restituição dos direitos violados. Especialmente, as políticas públicas de educação, saúde e assistência social, as quais são responsáveis pelos programas e serviços que correspondem àqueles citados nos enunciados das próprias Medidas e que são da alçada do executivo municipal, consoante os princípios da descentralização político-administrativa e da municipalização do atendimento. 
As Medidas de Proteção encontram-se relacionadas no Art. 101 do ECA e são:

I - encaminhamento aos pais ou responsável, mediante termo de responsabilidade;

II - orientação, apoio e acompanhamento temporários;

III - matrícula e frequência obrigatórias em estabelecimento oficial de ensino fundamental;

IV - inclusão em programa comunitário ou oficial de auxílio à família, à criança e ao adolescente;

$\mathrm{V}$ - requisição de tratamento médico, psicológico ou psiquiátrico, em regime hospitalar ou ambulatorial;

VI - inclusão em programa oficial ou comunitário de auxílio, orientação e tratamento a alcoólatras e toxicômanos;

[...] (BRASIL, 2010) ${ }^{9}$

E as Medidas Pertinentes aos Pais ou Responsável estão no Art. 129, as quais são:

I - encaminhamento a programa oficial ou comunitário de proteção à família;

II - inclusão em programa oficial ou comunitário de auxílio, orientação e tratamento a alcoólatras e toxicômanos;

III - encaminhamento a tratamento psicológico ou psiquiátrico;

IV - encaminhamento a cursos ou programas de orientação;

V - obrigação de matricular o filho ou pupilo e acompanhar sua frequiência e aproveitamento escolar;

VI - obrigação de encaminhar a criança ou adolescente a tratamento especializado;

VII - advertência;

[...] (BRASIL, 2010) $)^{10}$

Há reciprocidade entre os dois conjuntos de Medidas que são pertinentes às políticas de educação, saúde e assistência social, principalmente. O Encaminhamento aos pais ou responsável, mediante termo de responsabilidade é aplicada quando estes deixam de cumprir os deveres de assistir, criar e educar. Nessas circunstâncias, eles são notificados pelo CT para que compareçam à sede do órgão, a fim de serem informados da ameaça ou violação de direitos e para que assinem termo de responsabilidade comprometendo-se a cumprir seus deveres.

A Advertência é utilizada quando os pais ou responsável descumprem Medida anteriormente aplicada, sem fundamento ou por negligência, ou não atendem notificação do CT. O Termo de Advertência pode iniciar o pedido de perda da guarda, destituição da tutela e suspensão ou destituição do poder familiar. (BRASIL, 2010)

Exceto o Encaminhamento aos pais ou responsável e a Advertência, as demais Medidas exigem a oferta de serviços das políticas de assistência social, educação e saúde, sejam eles

\footnotetext{
${ }^{9}$ O CT não aplica as Medidas "VII - acolhimento institucional", "VIII - inclusão em programa de acolhimento familiar" e "IX - colocação em família substituta." (BRASIL, 2010).

${ }^{10}$ O CT não aplica as Medidas "VIII - perda da guarda", "IX - destituição da tutela" e "X - suspensão ou destituição do poder familiar". (BRASIL, 2010).
} 
operacionalizados no território do município, com abrangência regionalizada ou em regime de consórcio intermunicipal, como dispuser a legislação e o nível de gestão das políticas no município.

Em síntese, as Medidas aplicáveis pelo CT podem ser tipificadas em medidas de: a) orientação: encaminhamento de crianças e adolescentes aos pais mediante termo de responsabilidade, orientação e apoio temporários; b) inclusão: encaminhamento de crianças, adolescentes e pais para programas de orientação, cursos, tratamento de saúde e inserção na escola; c) coercitivas: obrigação de encaminhar crianças e adolescentes para tratamento especializado, obrigação de matricular os filhos na escola, requisição de serviços e advertência. E os destinatários de tais Medidas são crianças, adolescentes, pais, responsáveis e as instituições que formam a rede de serviços de proteção, ou seja, do Sistema de Garantia de Direitos.

A aplicação de Medidas às crianças e aos adolescentes visa restituir direitos, enquanto que a aplicação de Medidas aos pais, sobretudo as que denominamos de orientação e inclusão, implica em providenciar as condições adequadas para que eles possam cumprir o dever de assistência, criação e educação. Ao passo que as Medidas dirigidas às instituições e aos gestores visam interferir na oferta de serviços de políticas públicas ampliando o escopo de abrangência e de proteção social.

Em Santa Catarina, os dados indicam que a violação ocorre em relação a todos os direitos fundamentais, ou seja, à convivência familiar e comunitária; à educação, cultura, ao esporte e lazer; à liberdade, ao respeito e à dignidade; à vida e saúde; e à profissionalização e proteção no trabalho (SIPIA, 2011). Contexto que exige do CT a articulação com a rede de serviços das políticas sociais com vistas à restituição dos direitos. Porém, é neste momento em que são identificadas a ausência de serviços ou o esgarçamento da rede, indicando que o Estado também figura entre os agentes violadores, conforme será visto em seguida.

\section{AS LACUNAS DA REDE DE SERVIÇOS DE ASSISTÊNCIA SOCIAL}

Na política de assistência social estão situados vários serviços dos quais dependem o cumprimento de Medidas de Proteção e de Medidas aos Pais e Responsável. São exemplos os programas e serviços destinados a fornecer orientação e apoio social, apoio material à família, acolhimento para crianças e adolescentes, formação profissional e geração de renda. Em outras 
palavras, o CT aplica Medidas que são cumpridas mediante a inserção das famílias, crianças e adolescentes nestes programas e pela vialibilização dos serviços, quando inexistentes.

A Medida Orientação, apoio e acompanhamento temporários é aplicada pelo CT para a proteção de crianças e adolescentes quando os pais ou responsável, por si sós, não apresentam condições de cumprir seus deveres, quando suas capacidades se mostram insuficientes, evidenciando a necessidade de receberem suporte.

Assim como as crianças e os adolescentes, os pais também têm o direito à assistência social, por isso as Medidas Inclusão em programa comunitário ou oficial de auxílio à família, à criança e ao adolescente e Encaminhamento a programa oficial ou comunitário de proteção à família são aplicadas quando os pais ou responsável não têm recursos para exercerem os deveres do poder familiar. Segundo dispõe o Art. 23 do ECA, a "falta ou a carência de recursos materiais" não justificam a destituição do poder familiar (BRASIL, 2010, p. 5). Sob essas circunstâncias, os pais ou responsável devem receber proteção que lhes garanta as condições necessárias para o exercício de suas incumbências em respeito ao direito à convivência familiar e comunitária, direito de todos os membros da família. A Medida Encaminhamento a cursos ou programas de orientação também apresenta este caráter de possibilitar a melhoria das condições objetivas de vida dos pais, seja pela qualificação para a inserção profissional no mercado de trabalho, seja para estimular a criação de estratégias de geração de renda.

As principais lacunas apontadas na política de assistência social pelos conselheiros referiam-se, especialmente, aos programas de orientação e acompanhamento familiar e aos serviços de acolhimento. As queixas de que as famílias vivenciam dificuldades para educar os filhos, carecem de orientação sobre suas responsabilidades e as transferem para as escolas ou para os conselheiros foram repetitivas. Também foi apontada a ausência de conhecimento sobre o ECA, supostamente tomado como impeditivo às práticas educativas da família, bem como sobre o CT, utilizado pelos pais e outras instituições como mecanismo punitivo.

A política de assistência social ainda responde pelos serviços de acolhimento correspondentes às Medidas Acolhimento institucional e Inclusão em programa de acolhimento familiar, quando for diagnosticada a necessidade de afastamento de crianças e adolescentes de suas famílias. Embora estas Medidas não sejam da alçada do CT, cabe-lhe a fiscalização das instituições que prestam os respectivos serviços e a ação diante da inexistência ou da oferta irregular. 
Em Santa Catarina, o direito à convivência familiar e comunitária figurou como o principal direito violado no período entre janeiro de 1999 e março de 2011, totalizando 117.347 fatos (SIPIA, 2011). A violação deste direito inclui ausência de convívio (abandono, expulsão de casa, impedimento de acesso a pais ou irmãos entre outros), ausência de condições materiais para o convívio e inadequação do convívio (violência, convivência com pessoas dependentes de substâncias psicoativas entre outros).

Quanto aos serviços de acolhimento, os conselheiros mencionaram o fechamento de serviço em uma das Regionais da ACCT e o consequente despejo das crianças acolhidas, a ausência de serviços em outras duas Regionais e críticas ao serviço de acolhimento familiar, visto pelos gestores municipais como uma alternativa de baixo custo, sem atentar para os seus limites considerando-se as peculiaridades das demandas.

Outro aspecto a destacar refere-se à violação do Direito à profissionalização e proteção no trabalho, que ocupava o $5^{\circ}$ lugar na ordem de violações no Estado, com 6.329 registros (SIPIA, 2011). Nessa categoria estão adolescentes maiores de 16 anos em situação de trabalho sem a proteção legal ou em condições inadequadas, assim como a exploração de crianças e de adolescentes fora da idade permitida para o ingresso no mercado de trabalho. Acrescenta-se a este indicador a taxa de trabalho infantil, 9,88\% (IBGE, 2008) e as crianças e os adolescentes vinculados ao Programa de Erradicação do Trabalho Infantil, que somavam 19.234 em maio de 2011. (MDS, 2011).

As ocorrências verificadas em fiscalizações do Ministério do Trabalho e Emprego, que totalizaram 209 no ano de 2010, indicaram que os mais atingidos situavam-se na faixa etária entre 16 e 17 anos (133), seguido de 10 e 15 anos (75) e de 05 e 09 anos (01). (MTE, 2010). Crianças e adolescentes do sexo masculino predominavam neste grupo, com $85,64 \%$, enquanto que o índice do sexo feminino era de $14,36 \%$. Estes indicadores expressam que as políticas públicas são insuficientes para a proteção social, gerando demanda reprimida e a reiteração da violação de direitos de crianças e adolescentes, congruente com o que foi apontado pelos conselheiros tutelares.

Importante destacar que o reconhecimento da assistência social como direito social dos brasileiros deu-se com a Constituição Federal de 1988. Posteriormente, em 1993 foi aprovada a Lei Orgânica da Assistência Social (LOAS). Em 2004, com a Resolução nº 145 do Conselho Nacional de Assistência Social, foi criado o Sistema Único de Assistência Social (SUAS), que passou a vigorar em 2005. E, por fim, em 2011 o SUAS foi incorporado ao texto da LOAS. (BRASIL, 2011). 
Portanto, o processo de constituição da assistência social como política pública representa importante avanço no campo da proteção social, mas as dificuldades para a sua efetivação ainda são grandes.

\section{AS LACUNAS NA REDE DE SERVIÇOS DE EDUCAÇÃO}

$\mathrm{O}$ direito à educação, segundo define o Art. 53 do ECA, deve visar "ao pleno desenvolvimento" de crianças e adolescentes, ao "preparo para o exercício da cidadania e qualificação para o trabalho", compreendendo, conforme o Art. 54, o acesso ao "ensino fundamental, obrigatório e gratuito", a "progressiva extensão da obrigatoriedade e gratuidade ao ensino médio"11, o "atendimento educacional especializado aos portadores de deficiência, preferencialmente na rede regular de ensino", o "atendimento em creche e pré-escola", o "acesso aos níveis mais elevados do ensino, da pesquisa e da criação artística", a "oferta de ensino noturno regular, adequado às condições do adolescente trabalhador" e "programas suplementares de material didático-escolar, transporte, alimentação e assistência à saúde” (BRASIL, 2010, p. 17).

A Lei de Diretrizes e Bases da Educação, no Art. 21, estabelece dois níveis de educação escolar, sendo eles a educação básica, composta pela educação infantil, ensino fundamental e médio e a educação superior. Na sequência, no Art. 30, define que a educação infantil inclui o atendimento em creche para crianças com até 3 anos de idade e em pré-escola para crianças com 4 e 5 anos, pois aos 6 anos ocorre o ingresso no ensino fundamental cuja duração é de nove anos. Enquanto que o ensino médio tem duração de três anos e pode ser cursado paralelamente à educação profissional técnica (BRASIL, 2009a).

A organização da política de educação difere do modelo de sistema adotado pela saúde e assistência social, embora estejam estabelecidas distintas responsabilidades para os três entes federados, não há um sistema nacional com limites claros de atuação e instâncias de pactuação, e os Estados e municípios, principalmente, concorrem na oferta dos mesmos níveis de educação, como

\footnotetext{
${ }^{11}$ O ECA menciona como dever do Estado assegurar a "progressiva extensão da obrigatoriedade e gratuidade ao ensino médio", mas a Lei de Diretrizes e Bases da Educação, após as alterações instituídas pela Lei no. 12.061/2009, definiu como dever a "universalização do ensino médio gratuito" (BRASIL, 2009a). E a Emenda Constitucional nº 59/2009, tornou a educação básica obrigatória e gratuita dos 4 aos 17 anos de idade, com os mesmos programas suplementares já previstos para o ensino fundamental, a ser implementada até 2016 (BRASIL, 2009b).
} 
em Santa Catarina, onde as escolas municipais concentravam 47\% das matrículas no ensino fundamental em 2009 e as escolas estaduais 44,02\% (IBGE, 2009).

Considerando o disposto no ECA, até o momento, a educação infantil e o ensino fundamental estão entre os níveis do sistema educacional afetos diretamente à atuação do CT, em face da faixa etária que atendem. Todavia, a Medida de proteção faz referência especificamente ao ensino fundamental. Aspecto que deverá sofrer alterações em virtude da obrigatoriedade da educação básica e, portanto, da matrícula da população entre 4 e 17 anos, conforme a Emenda Constitucional no 59 (BRASIL, 2009b).

Fato preocupante é que tal mudança não tornou obrigatória a creche, uma das principais lacunas enfrentadas pelos Conselhos Tutelares e que poderá piorar com a pressão sobre os gestores municipais para cumprir a inserção de todas as crianças na pré-escola. Segundo Coelho (2010), em 2008 apenas $18,1 \%$ das crianças brasileiras de 0 a 3 anos estavam matriculadas em creche e $72,8 \%$ das crianças com 4 e 5 anos estavam na pré-escola, índices que na região Sul eram de 24,6\% e 59,4\% respectivamente. Como agravante da baixa cobertura, 33,9\% destas matrículas eram em estabelecimentos privados. Os municípios, que devem ofertar este nível de educação, respondem por $65,6 \%$ das vagas. Este vácuo tem impacto importante na proteção de crianças de famílias de baixa renda, pois as creches constituem espaços de cuidado, de segurança alimentar e de acesso à educação, ao mesmo tempo em que dão suporte para a inserção produtiva das mulheres e contribuem para impedir o abandono escolar de crianças maiores e de adolescentes que tendem a ser reponsabilizados pelos cuidados de seus irmãos.

A política de educação é responsável pela oferta de serviços correspondentes às Medidas Matrícula e frequência obrigatórias em estabelecimento oficial de ensino fundamental e Obrigação de matricular o filho ou pupilo e acompanhar sua frequência e aproveitamento escolar. A primeira é uma Medida de proteção aplicada pelo CT às crianças e aos adolescentes diante da ameaça ou da violação do direito à educação e a segunda é dirigida aos pais quando há descumprimento do Art. 55 do ECA, quando deixam de cumprir o dever de matricular o filho e acompanhar-lhe a frequência e o aproveitamento (BRASIL, 2010).

Fica evidente, pois, a interdependência entre a política de educação, as Medidas de proteção às crianças e aos adolescentes e aos pais e a atuação do CT. Sobretudo, quando verificamos que o direito à educação, cultura, ao esporte e lazer constitui o segundo direito com maior índice de violação em Santa Catarina no período entre 1999 e 2011, totalizando 38.535 fatos. 
Por ordem de incidência, os agentes violadores no âmbito da família são a mãe, o pai, os avós, o padrasto, os irmãos entre outros, enquanto que as creches e escolas são as instituições que figuram com maior registro de violações (SIPIA, 2011).

No âmbito da política de educação, os principais pontos de tensão foram constatados em torno das relações entre escolas e Conselhos Tutelares, mais especificamente, no que tange: - às queixas de negação de vagas; - ao repasse de responsabilidades da escola para o CT; - às dificuldades referentes à gestão das comunicações de infrequência e de evasão escolar; - à falta de recursos nas escolas.

O primeiro conjunto de violação de direitos refere-se à negação de vagas: - quando os pais pedem transferência de seus filhos para escolas situadas fora da área de abrangência, segundo o critério do zoneamento; - para alunos com distorção série e idade; - para adolescentes "praticantes de desordem", incluindo comportamentos de indisciplina e cometimento de ato infracional. No caso dos adolescentes que cometem ato infracional, o retorno à escola constitui uma Medida de Proteção aplicada pelo Juiz da Infância. Então, o embate é gerado pela determinação judicial, seguida pela pressão exercida pelo CT sobre as escolas para garantir o direito à educação.

O segundo conjunto de violação de direitos também está relacionado "aos praticantes de desordem". Os conselheiros alegam que as escolas tendem a não aplicar seus regimentos internos e encaminham as situações de indisciplina para que o CT gerencie conflitos entre os alunos e desses com os professores. Ou aplicam sanções como a suspensão e a transferência compulsória, que são consideradas medidas impeditivas do acesso à educação. E quando há prática de atos infracionais, as escolas demandam a intervenção do CT ao invés de acionarem a polícia. Nas duas circunstâncias os conselheiros são chamados a intervir em situações que não são pertinentes às suas atribuições.

De um lado, fica evidente que as escolas recorrem a uma autoridade externa para gerenciar situações que são de seu âmbito, mas para as quais não encontram soluções efetivas diferentes daquelas que eram tradicionalmente aplicadas, como a suspensão, a expulsão e a transferência compulsória. As quais são desaprovadas pelo CT pelo caráter meramente punitivo e por interferir ou impedir o acesso ao direito à educação. De outro lado, acionar a polícia e trazê-la para o espaço das escolas pode gerar insegurança e temor nos professores, alunos e na comunidade, além de tornálas vulneráveis às avaliações negativas e colocar em dúvida a sua imagem de local que fornece proteção. Demandar a ação do CT e não da polícia pode significar a proteção da escola destas formas de exposição nocivas, pois os impactos da presença de um órgão administrativo nos espaços 
escolares tende a ser menor do que a presença da força policial. Além desse aspecto, há que considerar os custos para os gestores das escolas em termos de tempo para: - deslocamento à Delegacia; - registro do Boletim de Ocorrência; - retornos para prestar depoimentos, entre outras ações que envolvem a tomada de providências para que o ato infracional seja apurado. Soma-se a falta de equipes técnicas nas escolas para intervir e dar suporte aos professores e gestores em situações como essas. Diante disso, não acionar a polícia nos casos de atos infracionais pode constituir uma estratégia para poupar tempo e recursos das escolas, assim como para preservá-la de desgastes relativamente à sua imagem.

O terceiro conjunto de violações apontado pelos conselheiros refere-se às dificuldades das duas instituições para gerenciar as comunicações de infrequência e de evasão. Conforme o Art. 56 do ECA, os dirigentes de estabelecimentos de ensino fundamental estão obrigados a comunicar ao CT a ocorrência de "maus-tratos envolvendo seus alunos", bem como a "reiteração de faltas injustificadas e de evasão escolar"12, após esgotados os recursos que a escola deve dispor, e os "elevados níveis de repetência”. (BRASIL, 2010, p. 18).

Segundo os conselheiros, há significativa resistência de parte das escolas em relação ao preenchimento do Aviso por Infrequência de Aluno e o seu encaminhamento em tempo hábil. Os formulários nem sempre indicam informações para a localização das famílias ou são encaminhados no final do ano, impossibilitando a tomada de providências para que os alunos possam retornar à escola ou, ainda, sem que as escolas tenham cumprido as atribuições que lhes cabem. Reconhecem, porém, que as famílias falham ao não fornecerem os endereços corretamente ou em não atualizá-los, bem como por não justificarem as faltas dos filhos. Indicando a existência de uma rede de interações entre conselheiros, gestores das escolas, alunos e famílias da qual resulta a violação do direito à educação e outras dela decorrentes.

Por fim, o último conjunto de violações situa-se nas lacunas da política de educação apontadas pelos conselheiros e pelos profissionais da educação, que encarregaram-se de reconhecer que as escolas não dispõem de recursos para desenvolverem as ações de busca de alunos evadidos ou faltosos, pois não há veículo e profissionais para as visitas às famílias. Os profissionais da educação também fizeram referência à universalização da educação e a consequente inclusão de crianças e adolescentes com deficiência e com habilidades especiais sem a adequação da

\footnotetext{
12 Em 2001 foi lançado o Programa de Combate à Evasão Escolar - APÓIA (Aviso por Infrequência de Aluno), coordenado pelo Centro de Apoio Operacional da Infância e Juventude do Ministério Público. (MINISTÉRIO PÚBLICO DO ESTADO DE SANTA CATARINA, 2007, p. 7).
} 
infraestrutura e das equipes para atendê-los, assim como a falta de serviços especializados para diagnóstico.

As tensões entre representantes da educação e conselheiros tutelares mostraram-se bastante visíveis, ambos queixavam-se mutuamente, cada qual apontando as limitações do outro e as próprias, estabelecendo uma espécie de duelo sem proposições para alterar o quadro vigente.

Em síntese, tanto as questões levantadas pelos conselheiros em relação às práticas das escolas, quando às lacunas identificadas pelos próprios agentes da política de educação, constituem indicativos que caracterizam violação de direitos, embora não tenhamos constatado manifestações dos conselheiros ali presentes no sentido de propor ações coletivas, ou seja, a capacidade de denúncia foi exercitada, tanto pelos conselheiros quanto pelos demais profissionais, mas não avançou na direção da restituição dos direitos violados. Assim como diante da principal lacuna da política de educação que é referente à falta de vagas na educação infantil e até mesmo a ausência deste tipo de serviço nos municípios. Silêncio que chama a atenção pelos seus desdobramentos, pois pode naturalizar as lacunas das políticas públicas com base no discurso de que é assim em todos os lugares, bem como tornar as queixas esvaziadas politicamente.

\section{AS LACUNAS DA REDE DE SERVIÇOS DE SAÚDE}

O cumprimento do direito à vida e à saúde, abordados nos Art. $7^{\circ}$ ao 14 do ECA, depende da oferta de serviços por parte do Sistema Único de Saúde (SUS) que vão da atenção básica à alta complexidade, como vacinação, "atendimento pré e perinatal” à gestante, apoio alimentar à gestante e à nutriz, "assistência psicológica à gestante e à mãe", exames para "diagnóstico e terapêutica de anormalidades no metabolismo do recém-nascido", atenção integral às crianças e aos adolescentes em todos os níveis de assistência, entre outros (BRASIL, 2010, p. 2-3). A violação de tais direitos exige a atuação do CT dirigida aos agentes violadores.

Dentre as Medidas de Proteção diretamente associadas à política de saúde e citadas no ECA estão a Requisição de tratamento médico, psicológico ou psiquiátrico, em regime hospitalar ou ambulatorial e a Inclusão em programa oficial ou comunitário de auxílio, orientação e tratamento a alcoolistas e toxicômanos. A primeira, a Requisição, é aplicada pelo CT quando os pais ou responsável não têm acesso aos serviços em razão da não oferta ou da falta de vagas. 
Como a Requisição é uma ordem, a aplicação desta Medida diante do não acesso pressupõe o atendimento imediato e a consequente restituição e garantia do direito até então violado, sob pena de representação à autoridade judiciária por descumprimento da deliberação. Mas quando o serviço está disponível e há recusa dos pais ou responsável, a Medida é cabível a eles, no caso, a Obrigação de encaminhar a criança ou adolescente a tratamento especializado, pois se trata de uma responsabilidade implícita no "dever de sustento, guarda e educação dos fillhos", segundo o Art. 22 do ECA (BRASIL, 2010, p. 4).

Quanto à Medida Inclusão em programa oficial ou comunitário de auxílio, orientação e tratamento a alcoolistas e toxicômanos, destina-se às crianças e aos adolescentes envolvidos com o uso de substâncias psicoativas. Do mesmo modo, pais ou responsável que apresentam dependência em substâncias psicoativas ou transtorno psíquico recebem Medida de Inclusão em programa oficial ou comunitário de auxílio, orientação e tratamento a alcoólatras e toxicômanos e Encaminhamento a tratamento psicológico ou psiquiátrico, a fim de restituir-lhes as condições para o exercício do poder familiar. Vale lembrar que o Art. 19 do ECA afirma que as crianças e os adolescentes têm o direito de ser criados e educados na família de origem ou substituta e "em ambiente livre da presença de pessoas dependentes de substâncias entorpecentes" (BRASIL, 2010, p. 4).

Estas Medidas requerem serviços da política de saúde mental e que estão distribuídos de forma hierarquizada, seguindo os níveis de complexidade do SUS. Portanto, são oferecidos na rede de atenção básica, em Centros de Atenção Psicossocial (CAPS) e hospitais. Ainda podem ser instalados Serviços Residenciais Terapêuticos, Centros de Convivência e Cultura e outros programas de incentivo à desinstitucionalização, à inserção social e à geração de renda.

Dos direitos fundamentais, o direito à vida e à saúde ocupa o quarto lugar no que tange à violação em Santa Catarina, com 10.135 fatos registrados. Manifesta-se pela falta de atendimento peri e pré-natal, emergencial, especializado, falta de equipamentos, de vacinação, entre outros. Mãe, pai, avós, padrasto e madrasta são os familiares apontados como os principais violadores. Enquanto que os postos de saúde, entidades de atendimento, hospitais e ambulatórios estão entre as instituições que cometem violações (SIPIA, 2011).

As lacunas tematizadas insistentemente pelos conselheiros eram referentes aos serviços para atendimento de crianças, adolescentes e pais dependentes de substâncias psicoativas. O quadro de violação descrito pelos conselheiros incluía: - internação psiquiátrica de adolescente em local muito distante do município, com implicações negativas para a manutenção dos vínculos familiares; 
- ausência de vagas em hospital psiquiátrico; - falta de pessoal especializado, incluindo psiquiatras; - inadequação das estruturas físicas hospitalares para atendimento de adolescentes, bem como a falta de professores para atendê-los durante o período de hospitalização; - falta de condições para acolhimento às famílias; - ausência de serviços de referência, como os CAPS, nos municípios com menos de 20 mil habitantes, que correspondem à maioria dos municípios catarinenses; descumprimento de requisição de serviços.

Entretanto, não foi possível concluir se as necessidades indicadas na área da saúde mental resultaram de constatações dos conselheiros com base em seus saberes ou da indicação de técnicos, pois vários depoimentos referiam-se à falta de vagas para internação hospitalar, quando a política de saúde mental prevê serviços ambulatoriais, CAPS, entre outros, e a prescrição cabe aos especialistas. Há a possibilidade, a ser investigada, de que a alta expectativa em relação à medicalização e à regulação por meio de leis sejam entendidas como estratégias para o enfrentamento de fenômenos que envolvem crianças e adolescentes. Observamos que a referência ao uso de bonés, de pulseiras coloridas associadas à prática sexual, à circulação de crianças e adolescentes nos espaços públicos, às fugas da escola para frequentar bares e à prática de ato infracional eram citadas de forma recorrente como matérias para a criação de leis ou como objetos de tratamento psicológico ou psiquiátrico.

A alta expectativa em relação à medicalização e aos procedimentos psiquiátricos e psicoterapêuticos pode ser um indicativo da dificuldade dos conselheiros em tomar estes fenômenos para análise sob outra perspectiva, ou seja, como formas de sociabilidade que têm sido construídas na contemporaneidade. Nesse caso, outras possibilidades de intervenção têm que ser exploradas e, por conseguinte, outros agentes de políticas públicas precisam ser implicados. Segundo Elia (2005, p. 53), o acolhimento das demandas por serviços de saúde mental para crianças e adolescentes na rede pública inclui o desafio de "desconstrução da demanda". Tal prática inclui intervenções com os responsáveis pelo encaminhamento, pois há casos de indisciplina escolar e de dificuldade de aprendizagem que são tratados como se fossem da alçada da saúde mental.

Os motivos que fundamentam as preocupações dos conselheiros tutelares estão relacionados ao envolvimento de crianças e adolescentes com substâncias psicoativas, tanto como usuários quanto como pessoas recrutadas para trabalhar no tráfico. E os conselheiros também reconhecem que há baixo investimento em programas de esporte e cultura, o que poderia ser um 
fator de proteção, segundo suas avaliações. Todavia, ações restitutivas a esse respeito não foram evidenciadas.

Associada ao envolvimento com substâncias psicoativas, a política de segurança pública também foi mencionada como deficitária, pois os adolescentes são incorporados ao sistema de tráfico para distribuir drogas, para fazer a vigilância de determinados locais e para assumir a propriedade de armas e de produtos quando apreendidos, isentando os adultos das responsabilidades.

A aproximação de crianças e, principalmente, de adolescentes com práticas ilícitas resulta, entre outros fatores, de processos de violação e, ao mesmo tempo, geram a violação do direito fundamental à vida, bem como do direito à liberdade, ao respeito e à dignidade, o terceiro conjunto de direitos com maior índice de violações no Estado, com 35.793 fatos (SIPIA, 2011). Nessa categoria estão incluídas práticas como o aliciamento de crianças e de adolescentes pela rede de tráfico de drogas para o porte de armas e para as práticas ilícitas ou impróprias, a violência, a exposição da imagem, tortura entre outros. Em relação a essas situações de violação, não há perspectiva de restituição dos direitos por meio de ações isoladas de uma ou outra política social ou do CT, muito menos no âmbito restrito dos municípios, o que gera sentimento de impotência, em conformidade com a posição de desânimo expressa por representante da Polícia Militar e dos conselheiros.

Ainda a esse respeito, outros temas foram abordados, como o toque de recolher e o rebaixamento da idade penal, vistos por alguns segmentos da sociedade, inclusive por conselheiros, como medidas para enfrentar o envolvimento com o tráfico e com a prática de ato infracional, reforçada pela ausência de uma rede de proteção para crianças e adolescentes para além das escolas e dos programas focalizados em segmentos pré-definidos.

\section{CONSIDERAÇÕES FINAIS}

Conforme exposto, o exercício da atribuição de atender crianças e adolescentes e aplicar Medidas de Proteção ou aos Pais prescinde de programas e serviços no âmbito do município, caso contrário, a atuação do CT terá impacto baixo na garantia ou restituição de direitos. Por outro lado, quando a política social não oferece os programas pertinentes, ou quando a rede não existe, ou 
quando a rede mostra-se esgarçada e com baixo potencial de proteção, o CT tem a responsabilidade de requisitar serviços para prover o atendimento de situações específicas e reivindicar investimentos para ampliar o escopo do atendimento e a melhoria da sua qualidade. Em caso de descumprimento da sua decisão, deve representar junto à autoridade judiciária.

A atuação do Conselho Tutelar, portanto, extrapola o âmbito das situações particulares, pois cabe comunicar ao Conselho Municipal de Direitos da Criança e do Adolescente a deficiência da rede de proteção e assessorar o executivo municipal por ocasião da elaboração do orçamento, de modo a contemplar os serviços de proteção cujas lacunas foram constatadas. Processo que poderá se alongar ou não se concretizar e, enquanto isso, é reiterada a violação de direitos.

O processo de observação em campo permitiu constatar que os conselheiros tutelares reconheceram as violações de direitos e as lacunas nas áreas da assistência social, educação e saúde. Porém, vimos que a ação do CT recai mais sobre as famílias do que sobre as instituições e mais em situações focalizadas e emergenciais do que em ações coletivas. Em síntese, sua capacidade de vocalização manifesta-se, em maior proporção, sob a forma de denúncia de violações como fatos isolados e que requerem respostas focalizadas. Em outras palavras, a capacidade de denúncia foi exercitada, mas não foram constatadas manifestações dos conselheiros no sentido de propor ações coletivas, ou seja, não avançaram na direção da restituição dos direitos violados. Silêncio que é significativo por se tratar de um órgão responsável por zelar pelos direitos fundamentais. Como desdobramento, esta posição no Sistema de Garantia de Direitos pode contribuir para a naturalização da negação de direitos por parte do Estado, bem como tornar as queixas individualizadas e esvaziadas politicamente, enfraquecendo os Conselhos Tutelares. Em síntese, o CT posiciona-se numa região fronteiriça, entre a defesa e a reiteração da violação de direitos de crianças e de adolescentes.

\section{REFERÊNCIAS}

BAPTISTA, M. V. Algumas reflexões sobre o sistema de garantia de direitos. Serviço social \& sociedade, São Paulo, n. 109, p. 179-199, jan./mar. 2012.

BOURDIEU, P. Coisas ditas. São Paulo: Brasiliense, 1987. 
BRASIL. Lei $\mathrm{n}^{\mathrm{o}}$. 8.069, de 13 de julho de 1990. Dispõe sobre o Estatuto da Criança e do Adolescente e dá outras providências. Florianópolis, Assembleia Legislativa do Estado de Santa Catarina, 2010.

Lei $n^{\circ}$. 9.394, de 20 de dezembro de 1996. Estabelece as diretrizes e bases da educação nacional, alterada pela Lei $n^{\circ}$. 12.061, de 27 de outubro de 2009. Presidência da República, Casa Civil, Brasília, 2009a. Disponível em: http://www.planalto.gov.br/ccivil_03/Leis/L9394.htm Acesso em: 16 nov. 2010.

Emenda Constitucional $n^{\circ} .59$, de 11 de novembro de 2009. Acrescenta $\S 3^{\circ}$ ao art. 76 do Ato das Disposições Constitucionais Transitórias para reduzir, anualmente, a partir do exercício de 2009, o percentual da Desvinculação das Receitas da União incidente sobre os recursos destinados à manutenção e desenvolvimento do ensino de que trata o art. 212 da Constituição Federal, dá nova redação aos incisos I e VII do art. 208, de forma a prever a obrigatoriedade do ensino de quatro a dezessete anos e ampliar a abrangência dos programas suplementares para todas as etapas da educação básica, e dá nova redação ao $\S 4^{\circ}$ do art. 211 e ao $\S 3^{\circ}$ do art. 212 e ao caput do art. 214 , com a inserção neste dispositivo de inciso VI. Presidência da República, Casa Civil, Brasília - DF, 2009b. Disponível em: 200.181.15.9/ccivil_03/Constituicao/Emendas/Emc/emc59.htm Acesso em: 13 jul. 2011.

Lei $\mathrm{n}^{\circ} .8 .742$, de 7 de dezembro de 1993, alterada pela Lei $\mathrm{n}^{\circ}$. 12.435, de 6 de junho de 2011. Dispõe sobre a organização da Assistência Social e dá outras providências. Disponível em: http://www.planalto.gov.br/ccivil_03/Leis/L8742.htm Acesso em: 15 jul. 2011.

Lei $n^{\circ} .12 .696$, de 25 de julho de 2012. Altera os arts. 132, 134, 135 e 139 da Lei no 8.069, de 13 de julho de 1990 (Estatuto da Criança e do Adolescente), para dispor sobre os Conselhos Tutelares. Disponível em: http://www.planalto.gov.br/ccivil_03/_Ato20112014/2012/Lei/L12696.htm Acesso em: 11 ago. 2012.

COELHO, R. C. Papel do Ministério da Educação na garantia da educação infantil (creche e préescola) na perspectiva da Emenda Constitucional $n^{\circ}$. 59/2009. In: Insumos para o debate 2 Emenda Constitucional $\mathbf{n}^{\mathbf{0}}$. 59/2009 e a educação infantil: impactos e perspectivas. São Paulo, Campanha Nacional pelo Direito à Educação, 2010. Disponível em: http://arquivo.campanhaeducacao.org.br/publicacoes/Insumos2_aBX.pdf Acesso em: 13 jul. 2011.

CONANDA. Resolução nº. 42, de 13 de outubro de 1995 (DOU Seção 1, de 17.10.95). Aprova as Diretrizes Nacionais para a Política de Atenção Integral à Infância e Adolescência nas áreas de Saúde, Educação, Assistência Social, Trabalho e para a Garantia de Direitos. Disponível em: http://www.dhnet.org.br/dados/cursos/dh/cc/3/crianca/diretrizes.htm Acesso em: 11 jun. 2010.

Parâmetros para a Criação e Funcionamento dos Conselhos Tutelares. Brasília, Ministério da Justiça/Secretaria de Estado dos Direitos Humanos, 2001. Disponível em: http://portal.mj.gov.br/sedh/ct/conanda/parametros1.htm Acesso em: 22 jun. 2007.

ELIA, L. A rede da atenção na saúde mental: articulações entre Caps e ambulatórios. In: BRASIL. Caminhos para uma política de saúde mental infanto-juvenil. Ministério da Saúde, Secretaria de 
Atenção à Saúde, Departamento de Ações Programáticas Estratégicas. Brasília: Editora do Ministério da Saúde, 2005.

ELIAS, N. Teoria simbólica. Tradução de Paulo Valverde. Oeiras: Celta Editora, 1994.

GOMES NETO, G. G. Palestra proferida na Conferência Regional para Conselheiros de Direitos e Conselheiros Tutelares em Chapecó (maio/97), Indaial (set./97), Barra Velha (abr./98) e Santo Amaro da Imperatriz (maio/98). Florianópolis, 2004. Disponível em: http://www.mp.sc.gov.br/portal/site/Portal/portal_detalhe.asp?campo=2451 Acesso em: 08 jun. 2010.

HAGUETTE, M. T. F. Metodologias qualitativas na sociologia. Petrópolis: Vozes, 1987.

IBGE. Instituto Brasileiro de Geografia e Estatística. PNAD - Pesquisa Nacional por Amostra de Domicílios $\quad$ - $2008 . \quad$ Disponível em: http://www.ibge.gov.br/home/presidencia/noticias/noticia_visualiza.php?id_noticia=1455\&id_pagi na Acesso em: 27 jul. 2010.

. Ensino, matrículas, docentes e rede escolar - 2009. Disponível em: http://www.ibge.gov.br/estadosat/temas Acesso em: 18 jul. 2011.

Pesquisa de Informações Básicas Municipais: Perfil dos Municípios Brasileiros - 2009. Rio de Janeiro, IBGE, 2010. Disponível em: http://www.ibge.gov.br/home/estatistica/economia/perfilmunic/2009/munic2009.pdf Acesso em: 23 mar. 2011.

MDS. Ministério do Desenvolvimento Social e Combate à Fome. MDS em Números - Santa Catarina - 2011. Disponível em: http://aplicacoes.mds.gov.br/sagi/ascom Acesso em: 16 jul. 2011.

MINISTÉRIO PÚBLICO DO ESTADO DE SANTA CATARINA. Plano geral de atuação 2007. Florianópolis, Procuradoria-Geral de Justiça, 2007. 40p. Disponível em: http://portal.mp.sc.gov.br/portal/conteudo/pgj/pga/pga2007internet.pdf Acesso em: 03 jul. 2010.

MIOTO, R. C. T. Cuidados sociais dirigidos à família e segmentos sociais vulneráveis. In: Capacitação em serviço social e política social: módulo 4. Programa de capacitação continuada para assistentes sociais. Brasília: CFESS/ABEPSS/CEAD/UnB, 2000.

MTE. Ministério do Trabalho e Emprego. SITI - Sistema de Informações sobre Focos de Trabalho Infantil $\quad$ 01/01 a 31/12/2010. Disponível em: http://sistemasiti.mte.gov.br/main_report.aspx Acesso em: 07 jul. 2011.

SANTA CATARINA. Lei $\mathrm{n}^{\circ}$. 12.362, de 11 de julho de 2002. Declara de utilidade pública a Associação Catarinense de Conselheiros Tutelares, em Curitibanos. Disponível em: http://200.192.66.20/alesc/docs/2002/12362_2002_Lei.doc Acesso em: 01 jun. 2011. 
SIPIA. Sistema para a Informação da Infância e Adolescência. Direitos violados e agentes violadores em Santa Catarina: 01/01/1999 - 24/03/2011. Disponível em: http://www.mj.gov.br/sipia/ Acesso em: 24 mar. 2011.

\title{
THE VOCALIZATION CAPACITY OF COUNCILS GUARDIANSHIP IN SANTA CATARINA
}

\begin{abstract}
This article deals about the constitution of the identity of the Guardianship Councils and their capacity to vocalization in the Child and Adolescent Rights Guarantee System. The capacity to vocalization is what helps to make visible the violation of rights of children and adolescents, giving them a voice and, at the same time, mark they position in defense of the enforcement of fundamental rights as stipulated in the Statute of Children and Adolescents. The methodological course included for participant observation at training seminars and meetings organized by the Santa Catarina Child Protection Association. We take the Rights Guarantee System as a setting within which the Council is forming the acquaintance of interdependence with other components in face of institutional incompleteness. We define the Guardian Council as a hybrid institution, a trait due to its purpose and characteristics as specified in the legislation that created it, potentiated by the infrastructure available for its installation and operation, and the safety net formed by public policies. Of this intersection of these structural elements results in a border identity, giving it a place between advocacy defense and reiteration of the violation. In Santa Catarina, the counselors highlighted the deficiencies in the safety net for children and adolescents, especially in social welfare policies, education and health. However, the gaps reported don't created actions that indicate that the exercise of call capacity to ensure the restoration of violated rights.
\end{abstract}

Key words: Child and Adolescent Rights Guarantee System. Child Protection Council. Capacity to vocalization. Configuration. 